\title{
A PARTICIPAÇÃO NO JULGAMENTO DE CASOS REPETITIVOS ${ }^{1}$
}

\section{PARTICIPATION IN TEST CASES}

João Paulo Lordelo Guimarães Tavares Graduado, mestre e doutor em Direito pela Universidade Federal da Bahia. Mestre em Direito Constitucional, na Universidad de Sevilla, Espanha. Pós-doutoramento pela Universidade de Coimbra, Portugal. Professor em diversos cursos de pósgraduação em Direito e preparatórios para carreiras jurídicas. Coordenador pedagógico e professor da Escola Superior do Ministério Público da União. Ex-Defensor Público Federal. Membro do Ministério Público Federal (Procurador da República). Editor do website www.joaolordelo.com. Salvador, Bahia, Brasil E-mail: joaolordelo@gmail.com.

RESUMO: O presente artigo tem por objetivo analisar as múltiplas formas de participação no julgamento de casos repetitivos, compreendido como uma espécie de processo coletivo, ao lado das ações coletivas. Para tanto, são utilizados conceitos fundamentais dos processos coletivos, a exemplo das noções de de grupo, membro do grupo e condutor do processo, os quais servirão de ponto de partida para a análise do catálogo legislativo. Ao longo do texto, são propostos meios dinâmicos e atípicos de intervenção, como forma de contornar o problema do déficit participativo. Por outro lado, para que se possa evitar uma indevida dilação processual, é proposta a atribuição de legitimação interventiva ad actum, a partir das circunstâncias do caso concreto.

PALAVRAS-CHAVE: Processos coletivos. Julgamento de casos repetitivos. Intervenção de terceiros. Déficit participativo. Legitimação ad actum.

ABSTRACT: The present article aims to analyze the multiple forms of participation in the

\footnotetext{
${ }^{1}$ Artigo recebido em 02/07/2020 e aprovado em 09/11/2020.
} 
judgment of test cases, understood as a kind of collective process, alongside class actions. For this, fundamental concepts of collective processes are used, such as the notions of group, group member and conductor of the process, which will serve as a starting point for the analysis of the legislative catalog. Throughout the text, dynamic and atypical means of intervention are proposed as a way of circumventing the problem of participatory deficit. On the other hand, in order to avoid undue procedural delay, it is proposed to assign interventional legitimation ad actum, based on the circumstances of the specific case.

KEY WORDS: Collective redress. Test cases. Participation. Participatory deficit. Legitimation ad actum.

\section{INTRODUÇÃO ${ }^{2}$}

É sabido que as sociedades contemporâneas são marcadas por relações jurídicas complexas e volumosas, a resultar em um forte incremento da quantidade de litígios. $\mathrm{O}$ acesso acelerado a novas tecnologias - e, consequentemente, a novos produtos e serviços de consumo -, bem como a ampliação dos meios de comunicação social e da educação jurídica são fatores que contribuem para o cenário ora vivenciado.

Nesse contexto, o legislador brasileiro, embora já houvesse editado a Lei da Ação Popular - LAP (Lei n. 4.717/1965) duas décadas antes, ocupou-se em desenvolver um microssistema processual coletivo a partir da década de 1980, por meio da Lei da Ação Civil Pública (Lei n. 7.437/1985) e do Código de Defesa do Consumidor (Lei n. 8.078/1990).

$\mathrm{O}$ modelo, contudo, não se revelou suficiente à solução dos problemas relativos à litigiosidade de massa.

Percebendo os limites inerentes às ações coletivas, diversos países estabeleceram,

\footnotetext{
2 Este artigo é resultado do grupo de pesquisa "Transformações nas teorias sobre o processo e o Direito processual", vinculado à Universidade Federal da Bahia e cadastrado no Diretório Nacional de Grupos de Pesquisa do CNPQ (dgp.cnpq.br/dgp/espelhogrupo/7958378616800053). Esse grupo é membro fundador da "ProcNet - Rede Internacional de Pesquisa sobre Justiça Civil e Processo contemporâneo" (http://laprocon.ufes.br/rede-de-pesquisa).
} 
adicionalmente, outros incidentes de coletivização, voltados ao julgamento, por amostragem, de demandas ou questões repetitivas. É o que se verifica no chamado aggregate procedure (também conhecido genericamente como group litigation), previsto, entre outros, na legislação de países como a Inglaterra e País de Gales (consolidation, joinder, test cases e Group Litigation Order), Estados Unidos (joinder e consolidation), Canadá (joinder or consolidation of multiple claims), Austrália (consolidation, joinder e test cases), Irlanda (consolidation, joinder e test cases), Alemanha (Musterverfahren), Áustria (Testprozess), Portugal, Japão e Suíça, observadas as particularidades de cada um deles.

O mesmo caminho foi adotado no Brasil, cujo Código de Processo Civil (CPC) de 1973, após a reforma promovida pela Lei n. 11.672/2008, passou a disciplinar os recursos especiais repetitivos. A potencialização do microssistema de julgamento de casos repetitivos viria por meio do CPC de 2015, ao estabelecer uma densa disciplina para os recursos extraordinário e especial repetitivos (REER), além de criar um instituto inteiramente novo, o incidente de resolução de demandas repetitivas (IRDR).

Nesse contexto, o objeto do presente trabalho recai sobre a disciplina das variadas formas de participação nos incidentes voltados ao julgamento de questões repetitivas (IRDR e REER), compreendidos como espécie do gênero "processos coletivos".

O estudo de tais incidentes tem demonstrado a relevância do papel do relator na fixação das diretrizes para a participação, inclusive mediante a designação de audiências públicas e a comunicação a outros legitimados coletivos e amici curiae, evitando-se o problema do déficit participativo, já anunciado por parte da doutrina.

\section{O JUlgamento de Casos RePetitivos COMO ESPÉCIE de PROCESSO COLETIVO}

O estudo das relações existentes entre as ações coletivas e o complexo sistema brasileiro de julgamento de casos repetitivos passa por uma questão de natureza prévia: o conceito de processo coletivo.

O processo, assim como outros institutos jurídicos, pode ser compreendido em mais de 
Revista Eletrônica de Direito Processual - REDP

Rio de Janeiro. Ano 15. Volume 22. Número 1. Janeiro a Abril de 2021

Periódico Quadrimestral da Pós-Graduação Stricto Sensu em Direito Processual da UERJ

Patrono: José Carlos Barbosa Moreira (in mem.). ISSN 1982-7636. pp. 465-487

www.redp.uerj.br

uma perspectiva, destacando-se ao menos três ${ }^{3}$ : tipo complexo de formação sucessiva (ato jurídico complexo ou simplesmente procedimento ${ }^{4}$ ), relação jurídica ${ }^{5}$ e técnica de criação de normas jurídicas ${ }^{6}$.

Nessa linha, também o processo coletivo, como um excerto do gênero processo jurisdicional, pode ser concebido como um "procedimento (ato complexo) destinado à produção da norma jurídica em razão do exercício da jurisdição"7 . A sua marca distintiva repousa no objeto litigioso, que envolve uma situação jurídica coletiva.

De acordo com a doutrina tradicional, processo coletivo é aquele conduzido por um sujeito processual especial em defesa de um direito coletivamente considerado, cuja imutabilidade do comando da sentença alcançará uma comunidade ou coletividade. A relação processual coletiva seria marcada, portanto, por três elementos: a afirmação de uma situação jurídica coletiva, a legitimidade extraordinária e a extensão dos efeitos da coisa julgada sobre

\footnotetext{
${ }^{3}$ A concepção tripartite do processo é defendida por Fredie Didier Jr., $c f$. DIDIER JR., Fredie. Sobre a teoria geral do processo: essa desconhecida. Salvador: JusPodivm, 2012, p. 68-75.

${ }^{4}$ Quanto a esse enfoque, nas lições de Élio Fazzalari, o processo poderia ser compreendido como "procedimento em contraditório" (FAZZALARI, Elio. Processo. Teoria generale. In: FAZZALARI, Elio. Novissimo Digesto Italiano, Torino, v. 13, 1996, p. 1.069). No particular, entendemos que tal ideia, embora bastante difundida, anuncia um conceito diverso: o de processo válido. É dizer: a presença ou não do contraditório (em maior ou menor grau) pode, à luz do direito posto, afetar o plano de validade da relação processual, não se tratando de um elemento conceitual. Firmada tal premissa, as fronteiras entre processo e procedimento resultam fragilizadas. Para uma melhor compreensão do tema, cf. BRAGA, Paula Sarno. Norma de processo e norma de procedimento: o problema da repartição de competência legislativa no plano do direito constitucional brasileiro. Salvador: JusPodivm, 2015.

${ }^{5}$ Registra Calmon de Passos que "nenhuma teoria é mais fecunda, em suas consequências, nem mais adequada, politicamente, para um Estado de direito democrático que a da relação jurídica" (PASSOS, José Joaquim Calmon de. Esboço de uma teoria das nulidades aplicada às nulidades processuais. Rio de Janeiro: Forense, 2005, p. 73). Como já havíamos referido em artigo dedicado aos negócios processuais, "concebendo-se o processo não apenas como uma, mas sim um conjunto de relações jurídicas estabelecidas entre os mais diversos sujeitos processuais (dentre eles as partes, o juiz, o Ministério Público e auxiliares), torna-se mais fácil importar todo o instrumental da teoria do fato jurídico - excerto da teoria geral do direito -, criando-se uma verdadeira teoria dos fatos jurídicos processuais" (TAVARES, João Paulo Lordelo Guimarães. A aplicação do instituto da colaboração premiada nas ações de improbidade administrativa. Revista de Processo, v. 284, p. 371-396, 2018).

${ }^{6}$ Cuida-se de enfoque extraído da teoria da norma jurídica. Nesse sentido, "o poder de criação de normas (poder normativo) somente pode ser exercido processualmente. Assim, fala-se em processo legislativo (produção de normas gerais pelo Poder Legislativo), processo administrativo (produção de normas gerais e individualizadas pela Administração) e processo jurisdicional (produção de normas pela jurisdição). É possível, ainda, conceber o processo negocial, método de criação de normas jurídicas pelo exercício da autonomia privada" (DIDIER JR., Fredie. Curso de Direito Processual Civil. 17. ed. Salvador: JusPodivm, 2015, v. 1, p. 30). Conferir, ainda, PASSOS, José Joaquim Calmon de. Comentários ao Código de Processo Civil. 8. ed. Rio de Janeiro: Forense, 1998, v. 3, p. 4.

${ }^{7}$ DIDIER JR., Fredie. Curso de Direito Processual Civil. 17. ed. Salvador: JusPodivm, 2015, v. 1, p. 30-33. Conferir ainda: DIDIER JR., Fredie; ZANETI JR., Hermes. Ações coletivas e o incidente de julgamento de casos repetitivos - espécies de processo coletivo no Direito brasileiro. In: DIDIER JR., Fredie; CUNHA, Leonardo Carneiro da (orgs.). Grandes temas do novo CPC: julgamento de casos repetitivos. Salvador: JusPodivm, 2017, v. 10 , p. 182.
} 
Revista Eletrônica de Direito Processual - REDP

Rio de Janeiro. Ano 15. Volume 22. Número 1. Janeiro a Abril de 2021

Periódico Quadrimestral da Pós-Graduação Stricto Sensu em Direito Processual da UERJ

Patrono: José Carlos Barbosa Moreira (in mem.). ISSN 1982-7636. pp. 465-487

www.redp.uerj.br

sujeitos que não participaram do processo $^{8}$.

Como explicam Fredie Didier Jr. e Hermes Zaneti Jr., não parece correto inserir, em tal conceito, as circunstâncias de ser instaurado por um legitimado autônomo e de ter um especial regime de coisa julgada, situações que, em realidade, também podem se fazer presentes em processos individuais ${ }^{9}$.

De fato, é possível encontrar legitimidade extraordinária também em processos individuais, a exemplo das ações de alimentos promovidas pelo Ministério Público no interesse de pessoa incapaz, algo bastante comum.

Além disso, o fato de a imutabilidade do comando da sentença atingir uma coletividade consiste em uma mera decorrência do objeto litigioso, na medida em que o titular da situação jurídica coletiva (ativa ou passiva) é um ente coletivo.

Em verdade, o regime da coisa julgada (limites objetivos, subjetivos e modo de produção) pode ser disciplinado pelo legislador da forma que compreender mais conveniente, independentemente do objeto litigioso.

Há ainda um relevante motivo para não se considerar a coisa julgada como um elemento essencial à caracterização do processo coletivo: a existência de técnicas processuais coletivas (e, portanto, de processos coletivos) cujo propósito não é a produção da coisa julgada, a exemplo do incidente de julgamento de casos repetitivos ${ }^{10}$ e os atos concertados (art. $69, \S 2^{\circ}$, do CPC).

Em razão disso, é possível conceituar o processo coletivo de forma mais ampla, tendo por particularidade o fato de nele ser postulado um direito coletivo em sentido amplo

\footnotetext{
${ }^{8}$ Nesse sentido: GIDI, Antonio. Coisa julgada e litispendência nas ações coletivas. São Paulo: Saraiva, 1995, p. 16.

9 “Assim, o processo coletivo é aquele em que se postula um direito coletivo lato sensu (situação jurídica coletiva ativa) ou se afirme a existência de uma situação jurídica coletiva passiva (deveres individuais homogêneos, p. ex.). Observe-se, então, que o núcleo do conceito de processo coletivo está em seu objeto litigioso: coletivo é o processo que tem por objeto litigioso uma situação jurídica coletiva ativa ou passiva. Essa distinção se distingue da proposta por Antonio Gidi, 'segundo pensamento, a ação coletiva é a proposta por um legitimado autônomo (legitimidade), em defesa de um direito coletivamente considerado (objeto), cuja imutabilidade do comando da sentença atingirá uma comunidade ou coletividade (coisa julgada) [...]" (DIDIER JR., Fredie; ZANETI JR., Hermes. Ações coletivas e o incidente de julgamento de casos repetitivos - espécies de processo coletivo no Direito brasileiro. In: DIDIER JR., Fredie; CUNHA, Leonardo Carneiro da (orgs.). Grandes temas do novo CPC: julgamento de casos repetitivos. Salvador: JusPodivm, 2017, v. 10, p. 183).

${ }^{10}$ DIDIER JR., Fredie; ZANETI JR., Hermes. Ações coletivas e o incidente de julgamento de casos repetitivos espécies de processo coletivo no Direito brasileiro. In: DIDIER JR., Fredie; CUNHA, Leonardo Carneiro da (orgs.). Grandes temas do novo CPC: julgamento de casos repetitivos. Salvador: JusPodivm, 2017, v. 10, p. 182.
} 
Revista Eletrônica de Direito Processual - REDP

Rio de Janeiro. Ano 15. Volume 22. Número 1. Janeiro a Abril de 2021

Periódico Quadrimestral da Pós-Graduação Stricto Sensu em Direito Processual da UERJ

Patrono: José Carlos Barbosa Moreira (in mem.). ISSN 1982-7636. pp. 465-487

www.redp.uerj.br

(situação jurídica coletiva ativa) ou a existência de uma situação jurídica coletiva passiva ${ }^{11}$.

$\mathrm{Na}$ doutrina estrangeira, nota-se que o conceito de processo coletivo é igualmente concebido de forma ampla, sem que se considerem os aspectos processuais ora afastados (legitimação e coisa julgada).

Nessa linha, o Access to Justice Act 1999, do Parlamento do Reino Unido, define as Multi-Party Action (MPA) como gênero, que compreende tanto as ações representativas ação "única" com o objetivo de solucionar questões comuns de fato ou de direito - quanto o julgamento coletivo de demandas individuais que apresentem questões comuns (aggregate proceedings $)^{12}$. É o que explica Joanne Blennerhasset, para quem o processo coletivo deve ser concebido em um sentido bastante amplo, de modo a abranger formas diversas de reparação coletiva (collective redress) ${ }^{13}$.

Embora, como visto, o conceito de processo coletivo seja algo bastante simples, não o é a sua disciplina jurídica. A normatização das interações entre o grupo titular do direito coletivo, os membros do grupo, o legitimado coletivo, as partes adversas, terceiros intervenientes e o órgão julgador compõem o devido processo legal coletivo, repleto de questionamentos sem expressas respostas legais ${ }^{14}$.

Somam-se a isso as variadas espécies de técnicas processuais coletivas utilizadas para a

\footnotetext{
${ }^{11}$ Não se desconhecem as opiniões doutrinárias que rejeitam a existência de ações coletivas passivas. Segundo Edilson Vitorelli, conquanto disseminado, o reconhecimento do processo coletivo passivo no Brasil "é equivocado e expressa uma compreensão errônea do conceito de ação coletiva passiva, tal como praticada nos Estados Unidos" (VITORELLI, Edilson. Ações coletivas passivas: por que elas não existem nem deveriam existir? Revista de Processo, São Paulo, v. 278, p. 297-335, 2018). O presente trabalho, contudo, orienta-se pelo reconhecimento da possibilidade de se atribuir a um sujeito coletivo um dever jurídico ou um estado de sujeição, o que pode ser concretizado por meio das ações coletivas passivas. Cuida-se de tema cuja explicação transborda os limites do objeto proposto. Para uma maior compreensão do assunto, $c f$. PEIXOTO, Ravi. Presente e futuro da coisa julgada no processo coletivo passivo: uma análise do sistema atual e as propostas dos anteprojetos. Revista de Processo, São Paulo, v. 256, p. 229-254, 2016.

${ }^{12}$ Como definido no Access to Justice Act 1999 (The Funding Code), “'Multi-Party Action' or 'MPA' means any action or actions in which a number of clients have causes of action which involve common issues of fact or law arising out of the same cause or event". Disponível em: http://www.opsi.gov.uk/si/si2000/70248906.htm. Acesso em: 23 dez. 2018.

13 "As ações multipartes são formas de procedimento coletivo que podem conduzir a um remédio ou ampliar o acesso a um remédio para danos em massa. Cuida-se de mecanismos judiciais que podem assumir diferentes formas. Uma delas é a 'ação coletiva' ou 'ação representativa', frequentemente utilizada em litígios civis em que se busca assegurar a reparação coletiva. [...]. Existem outras formas de procedimentos de litígios de grupo que precisam ser distinguidos das ações coletivas, situações em que os casos dos demandantes permanecem separados e distintos, mas são agrupados para gerenciamento coletivo, como o instituto inglês e galês do Group Litigation Order (GLO)" (BLENNERHASSET, Joanne. A Comparative Examination of Multi-Party Actions. Oxford e Portland: Hart Publishing, 2016, p. 13, tradução nossa).

${ }^{14}$ A respeito do devido processo legal coletivo, $c f$. VITORELLI, Edilson. O devido processo legal coletivo: dos direitos aos litígios coletivos. São Paulo: Revista dos Tribunais, 2016.
} 
solução de litígios que podem ostentar os mais diversos tons de complexidade.

Todas essas interações possuem íntima conexão com o objeto do presente trabalho, cuja compreensão demanda uma prévia exposição das premissas fundamentais dos processos coletivos.

\section{AS FORMAS DE INTERVENÇÃO NOS PROCESSOS COLETIVOS E A LEGITIMIDADE $A D A C T U M$}

\subsection{O CATÁLOGO LEGISLATIVO}

Em razão da natureza potencialmente multipolarizada dos processos coletivos, a envolver diversos agentes interessados, o seu campo permite uma variada e complexa gama de participações. Cuida-se de tema que deve ser considerado na decisão de saneamento e organização do processo coletivo, autorizando-se, de forma objetiva, meios adequados de ampliação do debate, atentando-se para que não seja comprometida a duração razoável do processo.

Nesse sentido, ganham destaque ao menos 11 (onze) formas participativas expressamente previstas em lei:

a) a intervenção de um colegitimado à propositura da ação coletiva como litisconsorte (art. $3^{\circ}, \S 5^{\circ}$, da Lei n. $7.853 / 1989$ e art. $5^{\circ}, \S 2^{\circ}$, da LACP);

b) a intervenção direta da própria coletividade em ação coletiva em curso (art. 232, caput, da CRFB/1988);

c) a intervenção móvel da pessoa jurídica interessada na ação popular e na ação de improbidade administrativa (art. $17, \S 3^{\circ}$, da Lei n. 8.429/1992 e art. $6^{\circ}$, $\S 3^{\circ}$, da Lei n. 4.717/1965);

d) a intervenção dos membros do grupo "como litisconsortes" nas ações coletivas voltadas à tutela de direitos individuais homogêneos (art. 94 do CDC);

e) a intervenção do Ministério Público como fiscal da ordem jurídica, em todos os processos coletivos (arts. 176, 976, $\S 2^{\circ}$, e 1.038, III, do CPC; art. $5^{\circ}, \S 2^{\circ}$, da LACP; e art. 92 do CDC);

f) a participação de experts durante audiências públicas (arts. 983, § $1^{\circ}$, e 1.038, II, 
Revista Eletrônica de Direito Processual - REDP

Rio de Janeiro. Ano 15. Volume 22. Número 1. Janeiro a Abril de 2021

Periódico Quadrimestral da Pós-Graduação Stricto Sensu em Direito Processual da UERJ

Patrono: José Carlos Barbosa Moreira (in mem.). ISSN 1982-7636. pp. 465-487

www.redp.uerj.br

do CPC);

g) a intervenção dos amici curiae (art. 138 do CPC);

h) a participação das partes das causas-piloto, nos incidentes de julgamento por amostragem (arts. 983 e 984, II, $a$, do CPC);

i) a participação dos terceiros intervenientes nas demandas escolhidas como causaspiloto (arts. 983 e 984, II, $b$, e art. 1.038, I, do CPC);

j) a intervenção dos membros de grupo partes dos processos sobrestados (arts. $983 \mathrm{e}$ 984, II, $b$, e art. 1.038, I, do CPC);

k) a intervenção de interessados na formação do precedente judicial (arts. 983 e 984, II, $b$, e art. 1.038, I, do CPC).

Cada uma das aludidas formas demanda uma análise particularizada, levando-se em conta a espécie de processo coletivo em tratativa.

\subsection{A PARTICIPAÇÃO NO JULGAMENTO DE CASOS REPETITIVOS}

\subsubsection{Déficit participativo no julgamento dos casos repetitivos}

O relator, nos incidentes voltados ao julgamento de casos repetitivos, possui a relevante tarefa de saneá-los e organizá-los, decidindo a respeito das formas interventivas.

Tais incidentes, como sabido, possuem natureza dúplice: servem, a um só tempo, à gestão de casos que ostentam questão jurídica repetitiva e à formação de precedente vinculante. É dizer, por meio da fixação de uma tese jurídica, não apenas são solucionadas as questões comuns que se apresentam nas causas pendentes, sendo também gestado um potencial precedente judicial, a partir da unidade fático-jurídica das causas-piloto e da interpretação a que chegou o tribunal a respeito da questão jurídica ${ }^{15}$.

Partindo-se dessa premissa, é possível constatar ao menos dois grupos de interessados na solução dessa questão comum: as partes dos processos sobrestados e os indivíduos interessados na formação do precedente ${ }^{16}$.

${ }^{15}$ DIDIER JR., Fredie; ZANETI JR., Hermes; ALVES, Gustavo Silva. Intervenção dos membros de grupo no julgamento de casos repetitivos. Civil Procedure Review, v. 10, n. 1, p. 54, 2019.

${ }_{16}$ BASTOS, Antonio Adonias Aguiar. O devido processo legal nas demandas repetitivas. 2012. 266 f. Tese (Doutorado em Direito) - Universidade Federal da Bahia, Faculdade de Direito, Salvador, 2012, p. 162. 
Revista Eletrônica de Direito Processual - REDP

Rio de Janeiro. Ano 15. Volume 22. Número 1. Janeiro a Abril de 2021

Periódico Quadrimestral da Pós-Graduação Stricto Sensu em Direito Processual da UERJ

Patrono: José Carlos Barbosa Moreira (in mem.). ISSN 1982-7636. pp. 465-487

www.redp.uerj.br

Somem-se a isso dois fatos legislativos relevantes.

O primeiro consiste na ausência, em tais procedimentos, da mesma preocupação legislativa quanto à adequada representação dos grupos juridicamente interessados na solução da questão, como ocorre nas ações coletivas.

O segundo consiste na ausência de previsão de um direito de retirada (right to opt-out). Isso significa reconhecer que os membros dos grupos interessados na certificação da questão comum e na formação do precedente não podem optar por se afastar do resultado do julgamento do procedimento coletivo, como ocorre nas ações coletivas, em que a opção pela continuidade do julgamento da demanda individual gera a renúncia da extensão da eficácia da decisão coletiva.

O resultado dessa soma não pode ser outro: seja no incidente de resolução de demandas repetitivas (IRDR), seja nos recursos especiais e extraordinários repetitivos (REER), é de extrema relevância a adoção de medidas tendentes à redução do déficit de contraditório durante o procedimento, sob pena de se ampliarem as objeções acerca dos efeitos do julgamento e da sua extensão subjetiva aos não participantes ${ }^{17}$.

Nesse sentido, ressaltam Fredie Didier Jr., Hermes Zaneti Jr. e Gustavo Silva Alves que, em tais instrumentos, as partes dos processos sobrestados estarão sujeitas à eficácia vinculativa pro et contra da tese jurídica, razão pela qual devem ser aprimorados os instrumentos participativos. De igual modo, deve ser possibilitada a presença dos indivíduos que poderão ser afetados pela eficácia vinculante do precedente judicial, sob pena de ficarem sujeitos ao resultado da estabilização de uma determinada interpretação jurídica de cuja construção não participaram ${ }^{18}$.

Cuida-se de uma imposição que deriva do contraditório como direito à participação pelo convencimento $^{19}$, podendo ser extraída também da regra de proibição de decisão-surpresa.

\footnotetext{
${ }^{17}$ É a preocupação de Antonio do Passo Cabral, para quem "devemos refletir sobre formas de fomentar a participação no incidente e reduzir os déficits de contraditório. Com isso, pensamos em neutralizar ou diminuir as objeções acerca dos efeitos do julgamento do incidente, e sua extensão objetiva aos não participantes" (CABRAL, Antonio do Passo. A escolha da causa-piloto nos incidentes de resolução de processos repetitivos. In: DIDIER JR., Fredie; CUNHA, Leonardo Carneiro da (orgs.). Grandes temas do novo CPC: julgamento de casos repetitivos. Salvador: JusPodivm, 2017, v. 10, p. 57).

${ }^{18}$ DIDIER JR., Fredie; ZANETI JR., Hermes; ALVES, Gustavo Silva. Intervenção dos membros de grupo no julgamento de casos repetitivos. Civil Procedure Review, v. 10, n. 1, p. 54, 2019.

${ }^{19}$ Conforme estabelecido pela Suprema Corte dos Estados Unidos no caso Mullane v. Central Hanover Bank \& Trust Co., não apenas o direito de ser notificado da existência de um processo, mas também o de ser ouvido de forma apropriada à natureza do caso integram o núcleo do devido processo legal: "Many controversies have
} 
Revista Eletrônica de Direito Processual - REDP

Rio de Janeiro. Ano 15. Volume 22. Número 1. Janeiro a Abril de 2021

Periódico Quadrimestral da Pós-Graduação Stricto Sensu em Direito Processual da UERJ

Patrono: José Carlos Barbosa Moreira (in mem.). ISSN 1982-7636. pp. 465-487

www.redp.uerj.br

Essa regra encontra previsão no art. 10 do CPC, ao dispor que "[o] juiz não pode decidir, em grau algum de jurisdição, com base em fundamento a respeito do qual não se tenha dado às partes oportunidade de se manifestar".

A decisão-surpresa, como sabido, é nula em relação às partes, por violação ao contraditório $^{20}$. Via de regra, quem não é parte não precisa se preocupar com esse tipo de decisão, em razão da ineficácia quanto à sua pessoa (eficácia inter partes da coisa julgada). No julgamento de casos repetitivos, contudo, nem as partes dos processos sobrestados nem os terceiros interessados na formação do precedente são as partes da causa-piloto. Apesar disso, por se tratar de incidentes de natureza coletiva, ficarão sujeitos aos seus efeitos, razão pela qual é razoável considerar que a decisão também será ao menos ineficaz em relação aos grupos que não foram adequadamente representados.

Nesse contexto, ganha destaque a regra do art. 979 do $\mathrm{CPC}$, ao dispor que a “instauração e o julgamento do incidente serão sucedidos da mais ampla e específica divulgação e publicidade, por meio de registro eletrônico no Conselho Nacional de Justiça".

Tal dispositivo revela um importante ponto de partida para fomentar a participação, a integrar a decisão de organização do julgamento de casos repetitivos: a adequada notificação ${ }^{21}$. Caberá ao relator do caso, em tal decisão, não apenas decidir a respeito dos pedidos de intervenção porventura existentes, mas também sobre a necessidade de ofertar prazo para a habilitação de mais interessados, evitando-se a sub-representação dos interesses em jogo.

\subsubsection{Formas interventivas comuns às ações coletivas}

\footnotetext{
raged about the cryptic and abstract words of the Due Process Clause, but there can be no doubt that, at a minimum, they require that deprivation of life, liberty or property by adjudication be preceded by notice and opportunity for hearing appropriate to the nature of the case" (ESTADOS UNIDOS. Suprema Corte. 339 U. S. $306,1950)$.

${ }^{20}$ OLIVEIRA, Carlos Alberto Alvaro de. Poderes do juiz e visão cooperativa do processo. Revista de Direito Processual Civil, n. 27, p. 28-29.

${ }^{21}$ Como revela Luiz Guilherme Marinoni, "esta ampla e incisiva comunicação da instauração do incidente, quando conjugada a sua necessária interpretação conforme o devido processo legal, oferece aos legitimados à tutela dos direitos individuais homogêneos oportunidade para intervir no processo como representantes adequados. Essa interpretação é conforme a Constituição, pois não há como ignorar a necessidade de os litigantes excluídos participarem mediante representantes adequados" (MARINONI, Luiz Guilherme. Incidente de resolução de demandas repetitivas. São Paulo: Revista dos Tribunais, 2016, p. 81).
} 
As formas interventivas relativas às ações coletivas também são aplicáveis ao julgamento de casos repetitivos, com fundamento nas suas respectivas regras, que integram o microssistema processual coletivo.

Assim, também é admitida a intervenção de um colegitimado (art. 977, II e III, do $\mathrm{CPC}^{22}$ ), valendo-se as observações relativas à excepcional intervenção da própria coletividade, à intervenção móvel da pessoa jurídica interessada, à intervenção do Ministério Público como fiscal da ordem jurídica, à participação de experts durante audiências públicas e aos amici curiae.

Merecem destaque, por outro lado, formas interventivas próprias.

\subsubsection{A intervenção dos membros de grupo partes dos processos sobrestados}

Os procedimentos de julgamento de casos repetitivos possuem natureza multipolar, podendo contar não apenas com diferentes grupos interessados, mas também subgrupos. A existência de um direito à certificação da questão jurídica repetitiva, por meio da fixação de uma tese comum, não implica a existência de unidade acerca da interpretação a ser empregada.

Nesse contexto, a identificação dos grupos e subgrupos interessados é uma tarefa relevante, demandando uma análise criteriosa do caso pelo relator, tendo em vista que "quanto maior for a participação dos respectivos representantes dos subgrupos, maiores serão as chances de que todos os fundamentos que cercam a questão sejam analisados"23. Em consequência, menores serão as chances de rediscussão da questão por ausência de um debate qualificado sobre os seus variados fundamentos.

Convém atentar ao disposto no art. $984, \S 2^{\circ}$, do CPC, pelo que "o conteúdo do acórdão abrangerá a análise de todos os fundamentos suscitados concernentes à tese jurídica discutida, sejam favoráveis ou contrários". A necessidade de serem analisados todos os fundamentos suscitados parte exatamente da premissa de que a amplitude do debate imprime maior

\footnotetext{
${ }^{22}$ Código de Processo Civil (Lei n. 13.105/2015): “Art. 977. O pedido de instauração do incidente será dirigido ao presidente de tribunal: [...] II - pelas partes, por petição; III - pelo Ministério Público ou pela Defensoria Pública, por petição".

${ }^{23}$ DIDIER JR., Fredie; ZANETI JR., Hermes; ALVES, Gustavo Silva. Intervenção dos membros de grupo no julgamento de casos repetitivos. Civil Procedure Review, v. 10, n. 1, p. 55, 2019.
} 
Revista Eletrônica de Direito Processual - REDP

Rio de Janeiro. Ano 15. Volume 22. Número 1. Janeiro a Abril de 2021

Periódico Quadrimestral da Pós-Graduação Stricto Sensu em Direito Processual da UERJ

Patrono: José Carlos Barbosa Moreira (in mem.). ISSN 1982-7636. pp. 465-487

www.redp.uerj.br

segurança ao precedente estabelecido.

Nessa linha, o art. 983, ao tratar das funções exercidas pelo relator no IRDR, estabelece uma cláusula geral de participações atípicas, ao dispor que ele "ouvirá as partes e os demais interessados", aí compreendidos os membros dos grupos que atuam como parte nos processos sobrestados ${ }^{24}$. De igual modo, o art. 1.038, I, ao disciplinar as funções do relator no REER, estabelece o poder de "solicitar ou admitir manifestação de pessoas, órgãos ou entidades com interesse na controvérsia". Cuida-se de regras extremamente relevantes, de modo a contornar o déficit de contraditório no julgamento de casos repetitivos.

Diferentemente do amicus curiae - que atua com fundamento no chamado interesse institucional, de modo pretensamente altruísta -, as partes nas demandas sobrestadas possuem interesse jurídico direto na certificação da questão comum. O objetivo da intervenção é bastante claro: tentar influenciar na fixação da tese jurídica que será aplicada em suas demandas. Assim - e diante do caráter genérico dos dispositivos acima referidos -, é relevante a definição da natureza (e, portanto, da extensão) dessa forma de participação.

Afastada a sua identificação como amicus curiae, o caminho natural seria o seu reconhecimento na qualidade de assistente litisconsorcial, como ocorre na intervenção dos membros do grupo nas ações coletivas relativas a pretensões individuais homogêneas.

A questão é controvertida.

De um lado, Bruno Dantas compreende que, ao se deparar com a suspensão de seu processo por força da instauração do IRDR, a parte "detém, tout court, interesse jurídico suficiente para viabilizar sua intervenção na qualidade de assistente simples"25.

De outro lado, Edilton Meireles defende que os interessados na controvérsia devem ser admitidos como assistentes simples ou litisconsorciais ${ }^{26}$.

\footnotetext{
${ }^{24}$ Para Rodolfo de Camargo Mancuso, a menção às "partes" se refere não apenas àqueles que assim figuram nas causas-piloto, mas também as partes dos processos sobrestados. Por outro lado, a menção aos "demais interessados" inclui as partes de outros processos, porventura não abrangidos no rol dos sobrestados, que contenham a mesma questão de direito objeto do IRDR (MANCUSO, Rodolfo de Camargo. Incidente de resolução de demandas repetitivas. São Paulo: Revista dos Tribunais, 2016, p. 258).

${ }^{25}$ DANTAS, Bruno. Comentários aos arts. 976 a 987 do CPC. In: WAMBIER, Teresa Arruda Alvim et al. (coords.). Breves comentários ao novo Código de Processo Civil. 3. ed. São Paulo: Revista dos Tribunais, 2016, p. 2.438 .

26 "O interesse aqui há de ser entendido como o da pessoa que pode intervir no feito como assistente simples ou litisconsorcial" (MEIRELES, Edilton. Do incidente de resolução de demandas repetitivas no processo civil brasileiro. In: DIDIER JR., Fredie; CUNHA, Leonardo Carneiro da (orgs.). Grandes temas do novo CPC: julgamento de casos repetitivos. Salvador: JusPodivm, 2017, v. 10, p. 120).
} 
Revista Eletrônica de Direito Processual - REDP

Rio de Janeiro. Ano 15. Volume 22. Número 1. Janeiro a Abril de 2021

Periódico Quadrimestral da Pós-Graduação Stricto Sensu em Direito Processual da UERJ

Patrono: José Carlos Barbosa Moreira (in mem.). ISSN 1982-7636. pp. 465-487

www.redp.uerj.br

Por fim, Fredie Didier Jr., Hermes Zaneti Jr. e Gustavo Silva Alves defendem se tratar de uma nova espécie de intervenção de terceiros. Tais autores partem da compreensão de que a assistência é uma modalidade de intervenção voluntária que decorre da existência de interesse jurídico do interveniente, aferido a partir da análise do direito material discutido em juízo. Assim, somente poderá intervir no processo quem possuir relação jurídica conexa ou dependente à relação que constitui objeto do processo em que pretende intervir.

Por um lado, a assistência simples tem lugar quando constatada a presença de interesse jurídico indireto do terceiro. De outro, o assistente litisconsorcial possui interesse jurídico direto na demanda.

Concluem os autores que classificar a intervenção dos membros do grupo como uma modalidade de assistência simples ou litisconsorcial não parece ser a opção mais adequada, na medida em que o IRDR e os REER não decidem as várias relações jurídicas decorrentes dos processos sobrestados, nem resolvem controvérsias que ainda nem foram levadas ao Poder Judiciário. Ao revés, com exceção do julgamento das causas-piloto, limitam-se à fixação de uma tese jurídica e à possível formação de um precedente judicial em relação à questão repetitiva de direito ${ }^{27}$.

Em termos mais simples, inexiste vínculo com a relação jurídica que está sendo discutida. Com frequência, as demandas são totalmente dessemelhantes em relação às partes, causa de pedir ou pedido, a exemplo dos casos em que o incidente discute questões de Direito Processual.

Essa corrente é compartilhada por Lucas Buril de Macêdo, para quem não há que se falar em possibilidade de intervenção na qualidade de assistente, por não haver relação jurídica entre as partes dos processos em que se desenvolve o incidente e as partes dos processos suspensos ${ }^{28}$.

De fato, o interesse subjacente à intervenção não diz respeito à relação jurídica discutida nas causas-piloto, mas sim à situação jurídica coletiva existente e à vinculação que decorrerá

\footnotetext{
${ }^{27}$ DIDIER JR., Fredie; ZANETI JR., Hermes; ALVES, Gustavo Silva. Intervenção dos membros de grupo no julgamento de casos repetitivos. Civil Procedure Review, v. 10, n. 1, p. 60, 2019.

${ }^{28}$ MACÊDO, Lucas Buril de. Precedentes judiciais e o direito processual civil. 2. ed. Salvador: JusPodivm, 2017, p. 453. No mesmo sentido, defende Sofia Temer que "[o] interesse não é justificado por qualquer vínculo de direito material (como na assistência), mas pelo vínculo do sujeito e sua esfera de direitos com o objeto do incidente, porque se trata da solução de uma questão de direito que (também) lhe diz respeito" (TEMER, Sofia. Incidente de resolução de demandas repetitivas. 2. ed. Salvador: JusPodivm, 2017, p. 180).
} 
Revista Eletrônica de Direito Processual - REDP

Rio de Janeiro. Ano 15. Volume 22. Número 1. Janeiro a Abril de 2021

Periódico Quadrimestral da Pós-Graduação Stricto Sensu em Direito Processual da UERJ

Patrono: José Carlos Barbosa Moreira (in mem.). ISSN 1982-7636. pp. 465-487

www.redp.uerj.br

do eventual precedente judicial firmado a respeito da questão comum. O interesse que motiva a intervenção não reside na solução do caso concreto, mas sim na enunciação da tese jurídica objeto do incidente, elemento essencial do acórdão ${ }^{29}$.

A lógica peculiar desse tipo de incidente, marcado pela unidade cognitiva seguida da reprodução da tese definida, revela a existência de um interesse jurídico igualmente peculiar do sujeito interveniente, diverso do interesse do membro do grupo que intervém nas ações coletivas que tenham por objeto pretensões individuais homogêneas ${ }^{30}$.

Nem mesmo a redação do caput do art. 119 do CPC, que disciplina o instituto da assistência, parece contribuir, ao exigir que o terceiro que pretende auxiliar uma das partes seja “juridicamente interessado em que a sentença seja favorável a uma delas”. Não é o caso. Repita-se: o terceiro possui interesse na fixação da tese (que, como visto, pode se limitar a uma questão processual), não se vinculando ao direito material da causa a ser julgada.

Antes da entrada em vigor do novo CPC, que inovou ao prever expressamente a participação em seus arts. 983 e 1.038, I, parcela da doutrina buscava contornar o problema por meio da reconstrução do conceito de interesse jurídico ${ }^{31}$, de modo a permitir a intervenção, por assistência simples, dos indivíduos interessados na fixação da tese ou na formação do precedente.

Como reforço a esse entendimento, a Consolidação das Leis do Trabalho (CLT), em razão de alteração promovida pela Lei n. 13.015/2014, passou a prever a possibilidade de o relator "admitir manifestação de pessoa, órgão ou entidade com interesse na controvérsia, inclusive como assistente simples, na forma da Lei n. 5.869, de 11 de janeiro de 1973 (Código de Processo Civil)", no julgamento dos recursos de revista repetitivos.

\footnotetext{
${ }^{29} \mathrm{O}$ art. 222 do Regimento Interno do Tribunal de Justiça do Estado da Bahia é um importante referencial para a definição dos elementos essenciais do acórdão que julga o IRDR: "Art. 222. São elementos essenciais do acórdão que julgar o incidente de resolução de demandas repetitivas ou o incidente de assunção de competência: I - o relatório, que conterá os nomes das partes, a identificação do caso, com a suma do pedido e da contestação, e o registro das principais ocorrências havidas no andamento do processo; II - a identificação das circunstâncias fáticas que ensejam a controvérsia em torno da questão jurídica; III - o índice com todos os fundamentos favoráveis e contrários à tese jurídica discutida; IV - a análise de todos os fundamentos contrários e favoráveis à tese jurídica discutida; V - os dispositivos normativos relacionados à questão discutida; VI - a enunciação da tese jurídica objeto do incidente; VII - a fundamentação para a solução do caso; VIII - o dispositivo, em que o Tribunal resolverá o caso que lhe foi submetido".

${ }^{30}$ Em tais ações, o terceiro objetiva a defesa de uma parte específica, possuindo vínculo direto com o direito material discutido.

${ }^{31}$ DIDIER JR., Fredie. Revisão do conceito de interesse jurídico que autoriza a assistência simples: intervenção para colaborar com a criação de precedente judicial. Análise de recente decisão do STF. Revista de Processo, v. 158, p. 279-281, 2018.
} 
Revista Eletrônica de Direito Processual - REDP

Rio de Janeiro. Ano 15. Volume 22. Número 1. Janeiro a Abril de 2021

Periódico Quadrimestral da Pós-Graduação Stricto Sensu em Direito Processual da UERJ

Patrono: José Carlos Barbosa Moreira (in mem.). ISSN 1982-7636. pp. 465-487

www.redp.uerj.br

Com o NCPC, contudo, somando-se a disciplina da assistência simples, do amicus curiae e as regras interventivas do julgamento de casos repetitivos, tornou-se não apenas desnecessário, mas também inadequado tratar essa forma de intervenção na modalidade de assistência simples ${ }^{32}$.

Essa disciplina inaugura, em verdade, uma nova espécie de intervenção de terceiros.

Chegando-se a tal conclusão, permanece o questionamento: a intervenção dos interessados na formação do precedente judicial apresenta a mesma natureza? Quais são os limites à admissão e à atuação dos intervenientes?

\subsubsection{A intervenção de interessados na formação do precedente judicial}

A diferença entre as partes dos processos sobrestados e os interessados na formação do precedente está no fato de que os membros do segundo grupo sequer ajuizaram suas respectivas demandas.

De forma exemplificativa, imagine-se um IRDR em que se discuta se os pressupostos para a inversão do ônus da prova do art. $6^{\circ}$, VIII, do CDC são cumulativos ou alternativos.

Nessa situação, as partes dos processos sobrestados já possuem uma demanda em curso, ou seja, um conflito a respeito de uma relação material concreta cujo resultado depende diretamente da solução da questão jurídica comum. Por outro lado, é possível conceber a existência de indivíduos que, conquanto não discutam a questão comum em demanda em concurso, sejam potencialmente atingidos pelo precedente judicial a ser formado.

Também essas pessoas estão abrangidas pelos arts. 983 e 1.038, I, do CPC, sujeitas à mesma modalidade interventiva ${ }^{33}$.

Mesmo antes da previsão de tais dispositivos, inaugurados pelo CPC de 2015, já se concebia a intervenção dos terceiros juridicamente interessados na formação do precedente.

\footnotetext{
${ }^{32}$ DIDIER JR., Fredie; ZANETI JR., Hermes; ALVES, Gustavo Silva. Intervenção dos membros de grupo no julgamento de casos repetitivos. Civil Procedure Review, v. 10, n. 1, p. 61, 2019.

${ }_{33}$ Em análise à regra do art. 983, caput, do CPC, registra Antonio do Passo Cabral que por "interessado" devemse compreender "pessoas, órgãos ou entidades que tenham interesse econômico ou indireto (e que, portanto, não configuraria o 'interesse jurídico' para fins de intervenções de terceiros, art. 119) e, bem assim, aqueles que demonstrarem interesse na formação do precedente, por exemplo, partes de processos individuais em que se discuta a questão comum objeto do incidente" (CABRAL, Antonio do Passo. Do incidente de resolução de demandas repetitivas. In: CABRAL, Antonio do Passo; CRAMER, Ronaldo (coords.). Comentários ao novo Código de Processo Civil. 2. ed. Rio de Janeiro: Forense, 2016, p. 1.460).
} 
Revista Eletrônica de Direito Processual - REDP

Rio de Janeiro. Ano 15. Volume 22. Número 1. Janeiro a Abril de 2021

Periódico Quadrimestral da Pós-Graduação Stricto Sensu em Direito Processual da UERJ

Patrono: José Carlos Barbosa Moreira (in mem.). ISSN 1982-7636. pp. 465-487

www.redp.uerj.br

Para Sérgio Cruz Arenhart, trata-se de uma interpretação ampliada do conceito de "interesse de intervenção", que, em prestígio ao contraditório, permite a intervenção de indivíduos não apenas no julgamento de casos repetitivos, mas também em outros casos que possam resultar em um precedente judicial vinculante ${ }^{34}$.

Esse entendimento foi positivado no âmbito do julgamento de casos repetitivos.

Surge, então, o questionamento sobre se esse grupo estaria em segundo lugar na ordem de preferência para fins de intervenção de terceiros, em comparação ao primeiro grupo, formado pelas partes dos processos sobrestados. Em outras palavras, havendo múltiplos interessados em intervir no processo, as partes dos processos sobrestados devem ter prioridade sobre os interessados na formação do precedente?

Não se pode negar que os membros do grupo formado pelas partes dos processos sobrestados têm ao seu lado a presunção de maior proximidade com o núcleo do interesse. Isso porque eles serão afetados diretamente pelo julgamento, ficando sujeitos à tese fixada, o que poderá definir diretamente o sucesso em seu processo individual.

Essa percepção faz com que haja, em favor desse grupo, uma presunção de que seus membros "tenham maior interesse na controvérsia, e, consequentemente, também garante maior grau de participação durante o trâmite do IRDR/REER" ${ }^{35}$.

Trata-se, porém, de uma presunção relativa, a atrair um maior ônus argumentativo para fins de demonstração da legitimidade interventiva por parte dos terceiros que não contem com demandas em trâmite.

A depender do caso concreto, o fato de alguém figurar como parte em um processo em curso, por si só, pode não ser suficiente para sobrepor os seus interesses em relação àqueles que não contam com ações ajuizadas. Basta imaginar um IRDR em que se discuta questão

\footnotetext{
34 “É certo que a ampliação desavisada do conceito de 'interesse de intervenção' pode tornar inviável a solução da lide, por gerar a invasão de terceiros no processo formado. Todavia, no outro vértice da questão, a não admissão desta intervenção ampliada acarretará a violação clara dos direitos de ampla defesa e contraditório de todos estes 'terceiros', que sofrerão (praticamente de forma imutável) os efeitos de uma decisão judicial, sem jamais ter condições de, efetivamente, opor-se a ela. De fato, não se pode admitir que o primeiro processo instaurado a respeito de certa controvérsia acabe por resultar em decisão que será indistintamente aplicada para todos os demais casos, sem que os titulares destes outros direitos tenham, de fato e de maneira concreta, a possibilidade de apresentar seus argumentos e interferir na decisão judicial" (ARENHART, Sérgio Cruz. O recurso de terceiro prejudicado e as decisões vinculantes. In: NERY JR., Nelson; WAMBIER, Teresa Arruda Alvim (coords.). Aspectos polêmicos e atuais dos recursos cíveis e assuntos afins. São Paulo: Revista dos Tribunais, v. 11, p. 436-437).

${ }^{35}$ DIDIER JR., Fredie; ZANETI JR., Hermes; ALVES, Gustavo Silva. Intervenção dos membros de grupo no julgamento de casos repetitivos. Civil Procedure Review, v. 10, n. 1, p. 68, 2019.
} 
Revista Eletrônica de Direito Processual - REDP

Rio de Janeiro. Ano 15. Volume 22. Número 1. Janeiro a Abril de 2021

Periódico Quadrimestral da Pós-Graduação Stricto Sensu em Direito Processual da UERJ

Patrono: José Carlos Barbosa Moreira (in mem.). ISSN 1982-7636. pp. 465-487

www.redp.uerj.br

jurídica relativa a um determinado serviço no mercado de consumo, não sendo razoável supor que um consumidor eventual que figure como parte em uma demanda deva ter um tratamento privilegiado, em comparação a uma prestadora de serviço recém-constituída que ainda não tenha sido demandada, mas cuja atividade econômica principal dependa diretamente da solução dessa questão.

\subsection{5 $O$ controle da legitimidade ad actum pelo relator no julgamento de casos repetitivos}

Por ocasião da decisão de organização do julgamento de casos repetitivos, poderá o relator definir critérios objetivos para a intervenção de interessados, sejam eles partes nos processos sobrestados ou não ${ }^{36}$.

De forma exemplificativa, em um incidente em que se discuta se uma determinada atividade econômica configura ou não hipótese de incidência de um determinado tributo, é possível limitar a intervenção apenas a um determinado número de pessoas, compreendidos somente os contribuintes habituais do tributo em questão. Ficariam de fora, assim, os contribuintes eventuais, em razão do reduzido interesse em relação àqueles que rotineiramente desenvolvem atividades objeto da controvérsia. Tais limitações podem ter como parâmetro não apenas aspectos subjetivos, mas também o tipo de ato a ser praticado no processo.

Com o objetivo de evitar um tumulto procedimental decorrente de uma intervenção multitudinária, é recomendável que o controle da legitimidade interventiva seja realizado para cada ato que se pretenda praticar ${ }^{37}$, por aplicação da noção de legitimidade ad actum $^{38}$. Assim, em vez de admitir a intervenção de uma única vez, ofertando, de forma irrestrita, a possibilidade de os membros do grupo praticarem todos os atos previstos em lei (manifestação escrita, juntada de documentos, requisição de diligências, realização de sustentação oral etc.), poderá o relator do IRDR ou REER exercer o controle da legitimidade em relação a cada ato que o membro pretenda praticar durante o trâmite do procedimento.

\footnotetext{
${ }^{36}$ Segundo defende Sofia Temer, um dos possíveis critérios objetivos seria justamente a existência de processos pendentes (TEMER, Sofia. Incidente de resolução de demandas repetitivas. 2. ed. Salvador: JusPodivm, 2017, p. 182). No particular, compreendemos que a admissibilidade de tal critério dependerá do caso concreto.

${ }^{37}$ DIDIER JR., Fredie; ZANETI JR., Hermes; ALVES, Gustavo Silva. Intervenção dos membros de grupo no julgamento de casos repetitivos. Civil Procedure Review, v. 10, n. 1, p. 65, 2019.

38 CABRAL, Antonio do Passo. Despolarização do processo e "zonas de interesse": sobre a migração entre polos da demanda. Revista Eletrônica do Ministério Público Federal, Brasília, ano I, n. 1, p. 8, 2009.
} 
Revista Eletrônica de Direito Processual - REDP

Rio de Janeiro. Ano 15. Volume 22. Número 1. Janeiro a Abril de 2021

Periódico Quadrimestral da Pós-Graduação Stricto Sensu em Direito Processual da UERJ

Patrono: José Carlos Barbosa Moreira (in mem.). ISSN 1982-7636. pp. 465-487

www.redp.uerj.br

Dois são os principais parâmetros a serem utilizados pelo relator para admitir a intervenção: a contribuição argumentativa e o grau de interesse na controvérsia.

Inicialmente, caberá ao interveniente a demonstração da relevância da sua intervenção para o ato que pretenda realizar, apresentando argumentos novos, que ainda não foram levantados pelas partes do incidente. A mera repetição de teses já discutidas demonstra a ausência de interesse-utilidade na intervenção, estando já adequadamente representado nos autos ${ }^{39}$

Ao analisar a contribuição argumentativa dos sujeitos intervenientes, é importante que o relator considere a possibilidade de participação de, ao menos, um representante de cada um dos grupos de interesse do processo multipolar. Tal medida servirá para que se concretize o disposto no art. $984, \S 2^{\circ}$, do CPC, ao dispor que o conteúdo do acórdão "abrangerá a análise de todos os fundamentos suscitados concernentes à tese jurídica discutida, sejam favoráveis ou contrários".

A necessidade de se garantir a maior representatividade possível não apenas previne um possível descumprimento futuro - sob a alegação de existência de um argumento não apreciado no incidente, apto a alterar a conclusão alcançada -, como também auxilia a decisão de admissibilidade dos requerimentos de revisão da tese (art. 986), que poderá remeter ao acórdão, para indicar que o precedente no IRDR apreciou os argumentos do requerente, afastando-se a suposta novidade necessária à mudança de entendimento ${ }^{40}$.

Para além da apresentação de novos argumentos e da necessidade de ser assegurada a adequada representação aos variados grupos de interesse, é possível que a expertise dos advogados seja considerada como parâmetro pelo relator, ao analisar o filtro da contribuição argumentativa. Isso poderá ocorrer especialmente nos casos em que um advogado possua comprovada experiência na controvérsia, nos moldes do sistema consagrado pela Federal Rule $23^{41}$.

Também o grau de interesse na controvérsia serve de critério para a análise interventiva.

\footnotetext{
${ }^{39}$ DIDIER JR., Fredie; ZANETI JR., Hermes; ALVES, Gustavo Silva. Intervenção dos membros de grupo no julgamento de casos repetitivos. Civil Procedure Review, v. 10, n. 1, p. 66, 2019.

${ }^{40}$ CABRAL, Antonio do Passo. Do incidente de resolução de demandas repetitivas. In: CABRAL, Antonio do Passo; CRAMER, Ronaldo (coords.). Comentários ao novo Código de Processo Civil. 2. ed. Rio de Janeiro: Forense, 2016, p. 1.463.

${ }^{41}$ DIDIER JR., Fredie; ZANETI JR., Hermes; ALVES, Gustavo Silva. Intervenção dos membros de grupo no julgamento de casos repetitivos. Civil Procedure Review, v. 10, n. 1, p. 67, 2019.
} 
Como já referido, a depender da questão jurídica posta, será possível identificar diferentes níveis de interesse. Com base nesse critério, poderá o relator definir os poderes dos intervenientes de forma mais restrita. É possível até mesmo fixá-los de forma desigual, de acordo com as características de cada um. Assim, v.g., aos membros do grupo formado pelas partes nos processos sobrestados poderão ser ofertadas faculdades mais amplas, em relação aos sujeitos interessados na formação do precedente.

\section{CONCLUSÃO}

Ao final do exposto, apresentam-se as seguintes conclusões, sem prejuízo de outras ilações realizadas ao longo do texto:

É possível conceituar o processo coletivo de forma ampla, tendo por particularidade o fato de nele ser postulado um direito coletivo em sentido amplo (situação jurídica coletiva ativa) ou a existência de uma situação jurídica coletiva passiva. Esse gênero abrange não apenas o julgamento das ações coletivas, mas também dos casos repetitivos.

As formas interventivas relativas às ações coletivas também são aplicáveis ao julgamento de casos repetitivos, com fundamento nas suas respectivas regras, que integram o microssistema processual coletivo.

Assim, também é admitida a intervenção de um colegitimado (art. 977, II e III, do CPC), valendo-se as observações relativas à excepcional intervenção da própria coletividade, à intervenção móvel da pessoa jurídica interessada, à intervenção do Ministério Público como fiscal da ordem jurídica, à participação de experts durante audiências públicas e aos amici curiae.

Merecem destaque, por outro lado, formas interventivas próprias do julgamento de casos repetitivos.

Tais incidentes possuem natureza dúplice: servem, a um só tempo, à gestão de casos que ostentam questão jurídica repetitiva e à formação de precedente vinculante. É dizer, por meio da fixação de uma tese jurídica, não apenas são solucionadas as questões comuns que se apresentam nas causas pendentes, sendo também gestado um potencial precedente judicial, a partir da unidade fático-jurídica das causas-piloto e da interpretação a que chegou o tribunal a respeito da questão jurídica. 
Partindo-se dessa premissa, é possível constatar ao menos dois grupos de interessados na solução dessa questão comum: as partes dos processos sobrestados e os indivíduos interessados na formação do precedente.

Somem-se a isso dois fatos legislativos relevantes.

O primeiro consiste na ausência, em tais procedimentos, da mesma preocupação legislativa quanto à adequada representação dos grupos juridicamente interessados na solução da questão, como ocorre nas ações coletivas.

O segundo consiste na ausência de previsão de um direito de retirada (right to opt-out). Isso significa reconhecer que os membros dos grupos interessados na certificação da questão comum e na formação do precedente não podem optar por se afastar do resultado do julgamento do procedimento coletivo, diversamente do que ocorre nas ações coletivas.

O resultado dessa soma não pode ser outro: seja no incidente de resolução de demandas repetitivas (IRDR), seja nos recursos especiais e extraordinários repetitivos (REER), é de extrema relevância a adoção de medidas tendentes à redução do déficit de contraditório durante o procedimento, sob pena de se ampliarem as objeções acerca dos efeitos do julgamento e da sua extensão subjetiva aos não participantes

Nessa linha, o art. 983, ao tratar das funções exercidas pelo relator no IRDR, estabelece uma cláusula geral de participações atípicas, ao dispor que ele "ouvirá as partes e os demais interessados", aí compreendidos os membros dos grupos que atuam como parte nos processos sobrestados.

Quanto a tais pessoas, não há que se falar em possibilidade de intervenção na qualidade de assistente, por não haver relação jurídica entre as partes dos processos em que se desenvolve o incidente e as partes dos processos suspensos.

Essa disciplina inaugura, em verdade, uma nova espécie de intervenção de terceiros. $\mathrm{O}$ interesse subjacente à intervenção não diz respeito à relação jurídica discutida nas causaspiloto, mas sim à situação jurídica coletiva existente e à vinculação que decorrerá do eventual precedente judicial firmado a respeito da questão comum. O interesse que motiva a intervenção não reside na solução do caso concreto, mas sim na enunciação da tese jurídica objeto do incidente, elemento essencial do acórdão.

A diferença entre as partes dos processos sobrestados e os interessados na formação do precedente está no fato de que os membros do segundo grupo sequer ajuizaram suas 
respectivas demandas.

Surge, então, o questionamento sobre se esse grupo estaria em segundo lugar na ordem de preferência para fins de intervenção de terceiros, em comparação ao primeiro grupo, formado pelas partes dos processos sobrestados.

Não se pode negar que os membros do grupo formado pelas partes dos processos sobrestados têm ao seu lado a presunção de maior proximidade com o núcleo do interesse. Trata-se, porém, de uma presunção relativa, a atrair um maior ônus argumentativo para fins de demonstração da legitimidade interventiva por parte dos terceiros que não contem com demandas em trâmite.

Com o objetivo de evitar um tumulto procedimental decorrente de uma intervenção multitudinária, é recomendável que o controle da legitimidade interventiva seja realizado para cada ato que se pretenda praticar, por aplicação da noção de legitimidade ad actum. Assim, em vez de admitir a intervenção de uma única vez, ofertando, de forma irrestrita, a possibilidade de os membros do grupo praticarem todos os atos previstos em lei (manifestação escrita, juntada de documentos, requisição de diligências, realização de sustentação oral etc.), poderá o relator do IRDR ou REER exercer o controle da legitimidade em relação a cada ato que o membro pretenda praticar durante o trâmite do procedimento.

\section{REFERÊNCIAS}

ARENHART, Sérgio Cruz. O recurso de terceiro prejudicado e as decisões vinculantes. In: NERY JR., Nelson; WAMBIER, Teresa Arruda Alvim (coords.). Aspectos polêmicos e atuais dos recursos cíveis e assuntos afins. São Paulo: Revista dos Tribunais, v. 11, p. 436-437.

BLENNERHASSET, Joanne. A Comparative Examination of Multi-Party Actions. Oxford e Portland: Hart Publishing, 2016.

BASTOS, Antonio Adonias Aguiar. O devido processo legal nas demandas repetitivas. 2012. 266 f. Tese (Doutorado em Direito) - Universidade Federal da Bahia, Faculdade de Direito, Salvador, 2012, p. 162. 
Revista Eletrônica de Direito Processual - REDP

Rio de Janeiro. Ano 15. Volume 22. Número 1. Janeiro a Abril de 2021

Periódico Quadrimestral da Pós-Graduação Stricto Sensu em Direito Processual da UERJ

Patrono: José Carlos Barbosa Moreira (in mem.). ISSN 1982-7636. pp. 465-487

www.redp.uerj.br

BRAGA, Paula Sarno. Norma de processo e norma de procedimento: o problema da repartição de competência legislativa no plano do direito constitucional brasileiro. Salvador: JusPodivm, 2015.

CABRAL, Antonio do Passo. A escolha da causa-piloto nos incidentes de resolução de processos repetitivos. In: DIDIER JR., Fredie; CUNHA, Leonardo Carneiro da (orgs.). Grandes temas do novo CPC: julgamento de casos repetitivos. Salvador: JusPodivm, 2017, v. 10 .

CABRAL, Antonio do Passo. Do incidente de resolução de demandas repetitivas. In: CABRAL, Antonio do Passo; CRAMER, Ronaldo (coords.). Comentários ao novo Código de Processo Civil. 2. ed. Rio de Janeiro: Forense, 2016.

CABRAL, Antonio do Passo. Despolarização do processo e "zonas de interesse": sobre a migração entre polos da demanda. Revista Eletrônica do Ministério Público Federal, Brasília, ano I, n. 1, p. 8, 2009.

DIDIER JR., Fredie. Sobre a teoria geral do processo: essa desconhecida. Salvador: JusPodivm, 2012.

DIDIER JR., Fredie. Curso de Direito Processual Civil. 17. ed. Salvador: JusPodivm, 2015, v. 1, p. 30). Conferir, ainda, PASSOS, José Joaquim Calmon de. Comentários ao Código de Processo Civil. 8. ed. Rio de Janeiro: Forense, 1998, v. 3.

DIDIER JR., Fredie; ZANETI JR., Hermes. Ações coletivas e o incidente de julgamento de casos repetitivos - espécies de processo coletivo no Direito brasileiro. In: DIDIER JR., Fredie; CUNHA, Leonardo Carneiro da (orgs.). Grandes temas do novo CPC: julgamento de casos repetitivos. Salvador: JusPodivm, 2017, v. 10.

DIDIER JR., Fredie. Curso de Direito Processual Civil. 17. ed. Salvador: JusPodivm, 2015, v. 1.

DIDIER JR., Fredie; ZANETI JR., Hermes. Ações coletivas e o incidente de julgamento de casos repetitivos - espécies de processo coletivo no Direito brasileiro. In: DIDIER JR., Fredie; CUNHA, Leonardo Carneiro da (orgs.). Grandes temas do novo CPC: julgamento de casos repetitivos. Salvador: JusPodivm, 2017, v. 10.

DIDIER JR., Fredie; ZANETI JR., Hermes; ALVES, Gustavo Silva. Intervenção dos membros de grupo no julgamento de casos repetitivos. Civil Procedure Review, v. 10, n. 1, p. 54, 2019. 
DIDIER JR., Fredie. Revisão do conceito de interesse jurídico que autoriza a assistência simples: intervenção para colaborar com a criação de precedente judicial. Análise de recente decisão do STF. Revista de Processo, v. 158, p. 279-281, 2018.

FAZZALARI, Elio. Processo. Teoria generale. In: FAZZALARI, Elio. Novissimo Digesto Italiano, Torino, v. 13, 1996.

GIDI, Antonio. Coisa julgada e litispendência nas ações coletivas. São Paulo: Saraiva, 1995.

MACÊDO, Lucas Buril de. Precedentes judiciais e o direito processual civil. 2. ed. Salvador: JusPodivm, 2017.

MANCUSO, Rodolfo de Camargo. Incidente de resolução de demandas repetitivas. São Paulo: Revista dos Tribunais, 2016

MARINONI, Luiz Guilherme. Incidente de resolução de demandas repetitivas. São Paulo: Revista dos Tribunais, 2016.

MEIRELES, Edilton. Do incidente de resolução de demandas repetitivas no processo civil brasileiro. In: DIDIER JR., Fredie; CUNHA, Leonardo Carneiro da (orgs.). Grandes temas do novo CPC: julgamento de casos repetitivos. Salvador: JusPodivm, 2017, v. 10

OLIVEIRA, Carlos Alberto Alvaro de. Poderes do juiz e visão cooperativa do processo. Revista de Direito Processual Civil, n. 27, p. 28-29.

PEIXOTO, Ravi. Presente e futuro da coisa julgada no processo coletivo passivo: uma análise do sistema atual e as propostas dos anteprojetos. Revista de Processo, São Paulo, v. 256, p. 229-254, 2016.

TAVARES, João Paulo Lordelo Guimarães. A aplicação do instituto da colaboração premiada nas ações de improbidade administrativa. Revista de Processo, v. 284, p. 371-396, 2018.

TEMER, Sofia. Incidente de resolução de demandas repetitivas. 2. ed. Salvador: JusPodivm, 2017.

VITORELLI, Edilson. Ações coletivas passivas: por que elas não existem nem deveriam existir? Revista de Processo, São Paulo, v. 278, p. 297-335, 2018

VITORELLI, Edilson. O devido processo legal coletivo: dos direitos aos litígios coletivos. São Paulo: Revista dos Tribunais, 2016. 